\title{
Anaesthetic Management of a Patient with Hereditary Angioedema
}

\author{
Mediha Türktan ${ }^{1}$, Ersel Güleç ${ }^{1}$, Zehra Hatipoğlu ${ }^{1}$, Çağatay Küçükbingöz ${ }^{1}$, Mustafa Yılmaz ${ }^{2}$, Yasemin Güneş ${ }^{1}$ \\ ${ }^{1}$ Department of Anaesthesiology and Reanimation, Çukurova University Faculty of Medicine, Adana, Turkey \\ ${ }^{2}$ Department of Paediatric Allergy and Immunology, Çukurova University Faculty of Medicine, Adana, Turkey
}

Hereditary angioedema (HAE) is a rare autosomal dominant disorder caused by reduced activity of the C1 esterase inhibitor. Clinically, angioedema most often involves the upper extremities, face, neck and larynx. The most common cause of death is asphyxia related to laryngeal oedema. Attacks are triggered by many factors such as trauma, stress, infections and hormonal fluctuations. C1 esterase inhibitor concentrates, fresh frozen plasma (FFP), androgen steroids, quinine pathway inhibitors and antifibrinolytics can be used as treatment. In this case report, the anaesthetic management of a patient with hereditary angioedema undergoing laminectomy surgery is reported.

Key Words: Hereditary angioedema, C1 esterase inhibitor, laminectomy

\section{Introduction}

$\mathrm{H}$ ereditary angioedema (HAE) is an inheritable disease developed due to $\mathrm{C} 1$ esterase inhibitor deficiency. HAE is rarely seen but may progresses with life-threatening complications. The most frequently observed symptom is painless, non-itching oedema and difficulty in breathing. Trauma ranks first among the triggering factors. $\mathrm{C} 1$ esterase inhibitors, fresh frozen plasma (FFP), androgen steroids, kinin pathway inhibitors, and antifibrinolytics can be used in the management of disease.

\section{Case Presentation}

On magnetic resonance imaging examination of a 46-year-old female patient, who was admitted to the Neurosurgery Polyclinic with the complaints of low back and leg pain, L5-S1 extrude disc herniation and compression on the left nerve were detected and a laminectomy was planned.

Her preoperative examination revealed that she had had attacks of painless swelling on her body, which did not regress with antihistaminic treatment, since her childhood. Moreover, she underwent a previous surgery due to goitre 17 years ago without any postoperative problem. She presented to our hospital with the complaints of abdominal pain and swelling in her face 5 years ago and her laboratory findings revealed a C3 level of $0.859 \mathrm{~g} \mathrm{~L}^{-1}\left(0.165-0.380 \mathrm{~g} \mathrm{~L}^{-1}\right)$, a C4 level of $<0.079$ $\mathrm{g} \mathrm{L}^{-1}\left(0.165-0.380 \mathrm{~g} \mathrm{~L}^{-1}\right)$, a C1 esterase level of $0.67 \mathrm{~g} \mathrm{~L}^{-1}\left(0.15-0.35 \mathrm{~g} \mathrm{~L}^{-1}\right)$, and a $\mathrm{C} 1$ esterase activity of $15 \%$ (70\%-130\%). Based on these findings, she was commenced on danazol (Danasin, Koçak Pharma, Turkey) with the pre-diagnosis of HAE. She was followed-up in the intensive care unit twice due to swelling of the tongue and lips after tooth extraction and received FFP for acute attacks particularly developed after trauma and stress. She lost her father due to same complaints, and her uncle, daughter of her uncle, her 1 brother and 4 sisters also had HAE.

No abnormal finding was determined on routine laboratory tests preoperatively. The patient was informed about the application of general or regional anaesthesia and possible complications. General anaesthesia application was decided based on the choice of the patient. Based on the recommendation of Immunology Unit, administration of C1 esterase inhibitor 1 hour preoperatively and, when necessary, intraoperative administration of FFP was planned. 
After obtaining patient consent in the operating room, routine monitorization (electrocardiography, peripheral oxygen saturation measurement) was performed. Invasive arterial catheterization was performed on the left arm considering that blood pressure cuff might lead to compression due to swelling on the right arm developed 2-3 days ago.

Propofol $\left(1.5 \mathrm{mg} \mathrm{kg}^{-1}\right)$ and rocuronium $\left(0.6 \mathrm{mg} \mathrm{kg}^{-1}\right)$ were used for anaesthesia induction. The patient was ventilated using a face mask without applying any pressure. Intubation was performed gently using a spiral endotracheal tube no: 7.5. The pilot balloon of the tube was inflated with the lowest pressure that prevents leakage. Anaesthesia maintenance was provided by $\mathrm{O}_{2}-\mathrm{N}_{2} \mathrm{O}$ and isoflurane $(0.8 \%-1 \%)$. Regions at risk for compression such as extremities and face were supported by silicone pillows, while the patient was in the prone position. Compression trauma was tried to be minimized by frequently controlling the patient's position during the intervention. Tramadol (100 mg IV) was administered for postoperative analgesia. At the end of the surgery, the patient with adequate spontaneous respiratory effort was extubated without straining after re-curarization. The patient was transferred to the intensive care unit for postoperative follow-up and then to the ward on the second day.

\section{Discussion}

Hereditary angioedema is a rare autosomal dominant disorder caused by $\mathrm{C} 1$ esterase inhibitor deficiency $(1,2)$. Its findings generally appear in school age and it is affected by hormonal fluctuations. HAE has a mild progress in males as androgens generally stimulate production of $\mathrm{C} 1$ esterase inhibitor (3). The most common symptom of HAE is painless, non-itching swelling. Skin lesions have a course of 2-5 days and prodromal symptoms such as feeling of tingling, and erythema marginatum can be observed. In the present patient, prodromal symptoms were not defined before the attack. Recurrent skin oedema, abdominal pain and larynx oedema are present in approximately $50 \%$ of adult patients (4). Mortality due to larynx oedema is encountered at a rate of $25-30 \%$. Rare clinical pictures such as pleural effusion, local brain oedema, and lung oedema can also be observed (5-7). While attacks can be triggered by stress, pressure, trauma, hormones, pregnancy, ACE inhibitors, alcohol consumption, and infection, they can also initiate spontaneously. Bradykinin is the key mediator playing a role in the pathogenesis (8).

Hypotension can develop due to sequestration of fluid in the extravascular area during severe attacks. Classic complement pathway and other pathways are activated in an uncontrolled way in $\mathrm{C} 1$ inhibitor deficiency. Level of C4, which is measured in screening test, is reduced during attacks and can be normal during other periods; however, it is not correlated with severity of attack. On the other hand, level of $\mathrm{C} 3$ is normal. In the present patients as well, the level of $\mathrm{C} 4$ was low and the level of C3 was normal during the attack. A major criterion and a laboratory criterion are sufficient for diagnosis
Table 1. Diagnostic criteria for hereditary angioedema due to $\mathrm{C} 1$ inhibitor deficiency

Clinical criteria

Major

(1) Recurrent, self-limiting, non-inflammatory subcutaneous angioedema without major urticarial-like rash, frequently lasting for more than 12 hours

(2) Self-healing, frequently recurring abdominal pain without an organic aetiology generally which lasts for more than 6 hours

(3) Recurrent laryngeal oedema

Minor

(1) Familial history

Laboratory criteria

(1) Levels of $\mathrm{C} 1$ esterase inhibitor being $50 \%$ of normal at least twice in the measurements performed after the age of 1 year

(2) Levels of functional C1-esterase inhibitor being $50 \%$ of normal at least twice in the measurements performed after the age of 1 year

(3) $\mathrm{C} 1$ inhibitor gene mutation that alters protein synthesis and/or function

Table 2. Clinical types of hereditary angioedema

\begin{tabular}{|llll|}
\hline & $\begin{array}{l}\text { C1 esterase } \\
\text { inhibitor level }\end{array}$ & $\begin{array}{l}\text { C1 esterase } \\
\text { inhibitor function }\end{array}$ & Frequency \\
\hline Type 1 & Low & Low & $80 \%-85 \%$ \\
\hline Type 2 & Normal & Low & $10 \%-15 \%$ \\
\hline Type 3 & Normal & Normal & $0 \%-10 \%$ \\
\hline
\end{tabular}

(Table 1). C1 inhibitor level plays a role in the clinical classification of disease (Table 2). Our patient was accepted to have type II HAE due to normal C1 inhibitor level $(0.67 \mathrm{~g}$ $\mathrm{L}^{-1}$ ) with low activity (15\%).

There are 3 main goals in the treatment: 1) Treatment of acute attack, 2) Long-term prophylaxis, 3) Prevention of attacks at periods with increased risk such as short-term prophylaxis and surgical intervention. The most important step in the treatment is to control the triggering factors (stress, trauma, infection). There is no special diet for the disease. Airway patency should be definitely maintained in respiratory tract involvement.

Drug therapy includes $\mathrm{C} 1$ esterase inhibitors, FFP, kinin pathway inhibitors, antifibrinolytic agents, androgen steroids, and spasmolytic preparations. C1 esterase inhibitors are the most commonly used agents in the treatment of acute attacks and for short-term prophylaxis (such as before tooth extraction and operation). C1 esterase inhibitors are produced from human plasma and have a half-life of 64 hours. Following intravenous administration of $\mathrm{C} 1$ esterase inhibitors, symptoms begin to regress within one hour. Administration of FFP $\left(10 \mathrm{~mL} \mathrm{~kg}^{-1}\right)$ is also an effective treatment choice, where $\mathrm{C} 1$ esterase inhibitors are unavailable (9-11). In the present patient, 2 × 500 unit $\mathrm{C} 1$ esterase inhibitor (Cetor, Centurion Pharma, Netherlands) was administered 1 hour before the intervention and FFP was not required during the 
surgery. In order to prevent their adverse effects (anaphylactoid reactions, redness, fever, headache, fatigue), $\mathrm{C} 1$ esterase inhibitors should be applied within the shortest time and slowly $\left(1 \mathrm{~mL} \mathrm{~min}^{-1}\right)$ after bringing them up to room temperature. In the present patient, no adverse effect due to $\mathrm{C} 1$ esterase inhibitor was observed. Androgen steroids (Danazol) are used frequently for long-term prophylaxis; they decrease attack frequency and severity. Treatment is started at a high dose (400-600 $\left.\mathrm{mg} \mathrm{day}^{-1}\right)$ and the dose is reduced according to the response. The treatment $\left(600 \mathrm{mg} \mathrm{day}^{-1}\right) \mathrm{can}$ be started 1 week before intervention for short-term prophylaxis (12). Our patient was on regular danazol (1 x $200 \mathrm{mg}$ ).

Preoperative follow-up of patients with HAE is quite important. Preoperative treatment is recommended particularly before dental interventions, endotracheal intubation, and endoscopy due to the risk of angioedema development and life-threatening larynx oedema. There is no precise information in the literature regarding the superiority of regional or general anaesthesia (13-15). The most common reasons for attacks during surgery are compression-related traumas and stress. As patient is cooperative and can change the position of extremities and face particularly, compression-related complications may be less in regional anaesthesia. However, in this case, a possible patient-related problem (such as impairment of haemodynamics, airway obstruction, and prolongation of the procedure) makes anaesthesia method difficult. In the present case, general anaesthesia was preferred due to the position of our patient and during the anaesthesia, we paid attention to face mask not to cause a high compression, to apply endotracheal intubation gently, to use an appropriatesized tube, and not to inflate the pilot balloon of the tube more than necessary. While positioning the patient, regions at risk for compression (nose, eye contour, extremities) were supported by silicone pillows. Postoperatively, after adequate spontaneous respiration was observed, our patient was extubated without any problem.

\section{Conclusion}

Patients with HAE should be closely followed-up regarding anaesthesia. Although there is no precise information regarding the anaesthesia method and anaesthetic agents to be used recently, the anaesthesia method should be selected according to surgery type and patient surgeon-anaesthetist opinions. Problem-free peroperative and postoperative management is possible with effective drug therapy, appropriate prophylaxis, and adequate precautions.

Informed Consent: Written informed consent was obtained from patient who participated in this case.
Peer-review: Externally peer-reviewed.

Author Contributions: Concept - Y.G., M.T.; Design - M.T.; Supervision - Y.G.; Funding - M.T., E.G.; Materials - Ç.K., M.Y., E.G.; Data Collection and/or Processing - Ç.K., M.Y.; Analysis and/or Interpretation - M.T.; Literature Review - M.T.; Writer - M.T.; Critical Review - Y.G., Z.H.; Other - M.Y., E.G., Z.H.

Conflict of Interest: No conflict of interest was declared by the authors.

Financial Disclosure: The authors declared that this study has received no financial support.

\section{References}

1. Bork K, Meng G, Staubach P, Hardt J. Treatment with C1 inhibitor concentrate in abdominal pain attacks of patients with hereditary angioedema. Transfusion 2005; 80: 1774-84. [CrossRef]

2. Visentin DE, Yang WH, Karsh J. C1-esterase inhibitor transfusions in patients with hereditary angioedema. Ann Allergy Asthma Immunol 1998; 80: 457-61. [CrossRef]

3. Cicardi M, Agostoni A. Hereditary angioedema. N Engl J Med 1996; 334: 1666-7. [CrossRef]

4. Agostoni A, Cicardi M. Hereditary and acquired C1-inhibitor deficiency: biological and clinical characteristics in 235 patients. Medicine (Baltimore) 1992; 71: 206-15. [CrossRef]

5. Frank MM, Gelfand JA, Atkinson JP. Hereditary angioedema: the clinical syndrome and its management. Ann Intern Med 1976; 84: 580-93. [CrossRef]

6. Landerman NS. Hereditary angioneurotic edema, I: case reports and review of the literature. J Allergy 1962; 33: 316-29. [CrossRef]

7. Legendre M, Chiche JF, Molina C, Grouffal C, Betail G. Respiratory manifestations in hereditary angioneurotic edema. Rev Pneumol Clin 1985; 41: 251-8.

8. Cicardi M, Banerji A, Bracho F, Malbrán A, Rosenkranz B, Riedl $M$, et al. Icatibant, a new bradykinin-receptor antagonist, in hereditary angioedema. N Engl J Med 2010; 363: 532-41. [CrossRef]

9. Degroote DF, Smith GL, Huttula GS. Acute airway obstruction following tooth extraction in hereditary angioedema. J Oral Maxillofac Surg 1985; 43: 52-4. [CrossRef]

10. Atkinson JC, Frank MM. Oral manifestations and dental management of patients with hereditary angioedema. J Oral Pathol Med 1991; 20: 139-42. [CrossRef]

11. Phillips KM, Glick M, Cohen SG. Hereditary angioedema: report of case. Spec Care Dentist 1989; 9: 23-6. [CrossRef]

12. Cicardi M, Zingale L. How do we treat patients with hereditary angioedema. Transfus Apher Sci 2003; 29: 221-7. [CrossRef]

13. Moraes RS, Vieira AS, Primo LG. Management of a dentigerous cyst in a child with hereditary angioedema. J Dent Child (Chic) 2010; 77: 59-63.

14. Yazawa T, O'higashi T, Daijo H, Shinomura T. Anesthesia management for emergency laparotomy in a pediatric patient with suspected hereditary angioedema. J Anesth 2010; 24: 121-3. [CrossRef]

15. Spargo PM, Smith GB. Hereditary angioneurotic oedema, tracheal intubation and airway obstruction. Can J Anaesth 1987; 34: 540-1. [CrossRef] 